Legality of circumcision in South Africa To the Editor: We read with interest David McQuoid-Mason's article $^{[1]}$ concerning the legality of circumcision in South Africa in terms of the Constitution and the Children's Act. Unfortunately, his statement that circumcision could lead to 'reversal in the gains made against HIV infection' shows that his piece is one of proselytism, not scholarship. ${ }^{[2]}$ Like the AIDS deniers before him, McQuoid-Mason repudiates strong scientific evidence, global public health authorities and the World Health Organization, which has endorsed circumcision as a priority preventive intervention in the struggle against HIV.

All medical interventions have elements of risk and benefit. Many of the preventive interventions that we routinely recommend for our patients have some degree of risk, but we recommend them when scientific evidence clearly demonstrates that the benefits outweigh the risks. Immunisations are a good example of this practice. We recommend immunisations for children, in spite of the small risk of adverse events, because the benefits far outweigh the risks - this despite the facts that many children will never be exposed to the agent in question, and that some children will become infected despite vaccination.

Ironically, the same issue of the SAMJ contains an article about human papillomavirus (HPV) vaccine in 9 - 12-year-old girls in KwaZulu-Natal, South Africa. ${ }^{[3]}$ McQuoid-Mason's flawed arguments concerning circumcision could equally be applied to the HPV vaccine: it is administered to children, carries small risks and is not $100 \%$ effective, and condoms will still need to be used in spite of vaccination.

Neonatal circumcision was recently upheld by legislation in Germany and by legislation and the courts in the USA. ${ }^{[4]}$ McQuoid-Mason's piece has done a grave disservice to global public health by failing to present a balanced view of this important medical and religious procedure.

Peter S Millard

Catholic University of Mozambique

pmillard@mac.com

\title{
Norman Goldstuck
}

Department of Obstetrics and Gynaecology, Tygerberg Hospital, Cape Town, South Africa

1. McQuoid-Mason DJ. Is the mass circumcision drive in KwaZulu-Natal involving neonates and children less than 16 years of age legal? What should doctors do? S Afr Med J 2013;103(5):283-284. [http://dx.doi.org/10.7196/SAMJ.6701]

2. Kesinger M. Millard PS. Voluntary male medical circumcision. S Afr Med J 2012;102(3):123-124

3. Moodley I, Mubaiwa V, Tathiah N, Denny L. High uptake of Gardasil vaccine among $9-12$-year-old schoolgirls participating in an HPV vaccination demonstration project in KwaZulu-Natal Province. S Afr Med J 2013;103(5):318-321. [http://dx.doi.org/10.7196/SAMJ.6414]

4. Wikipedia contributors. Circumcision and Law. Wikipedia, The Free Encyclopedia. http://en.wikipedia. $\mathrm{org} / \mathrm{w} /$ index.php?title=Circumcision_and_law\&oldid=557889424 (accessed 3 June 2013).

S Afr Med J 2013;103(7):436. DOI:10.7196/SAMJ.7115 